To the Editors:

\title{
A novel mode of paraquat poisoning
}

Pesticide poisoning from occupational, accidental and intentional exposure is a major public health problem in the developing world [1]. People are exposed to danger by hazardous occupational practices and unsafe storage. Paraquat is a widely used bipyridyl non-selective contact herbicide which has been in use since 1962 [2,3]. This is a water-soluble quaternary ammonium derivative.

Alcohol is recognised as a co-substance consumed in relation to agrochemicals in acute ingestion of poisons. Poisoning directly related to alcohol consumption is mainly due to the presence of methanol as an adulterous substance. Ethanol itself could cause poisoning in patients with high levels of intoxication. Kasippu is an illicit brew in Sri Lanka. The industry functions secretly in forests and mangroves to evade the law enforcement authorities. Depending on availability, fruits and other substances are known to be mixed with the brew. Anecdotal evidence exists on the practice of adding ingredients such as barbed wire, mosquito coils, cement and urea to the initial fermentory mixture, in the belief that they act as catalysts to enhance the strength of the alcohol. Here, I report a novel catalyst used in this illicit brew.

Five deaths occurred in a small hamlet close to Kandy where it was suspected that an illicit brew, consumed by all of the deceased when attending a village funeral, had poison mixed with it. Subsequent to these five deaths, 58 people from that village who became apprehensive sought admission to hospital. Twenty of them were asymptomatic. 
Some had abdominal pain, dyspnoea, faintishness and blurring of vision. Two of them died. Their post mortems showed the typical paraquat tongue and hemorrhagic changes in the lungs. There was sloughing of the oesophagus. The liver showed necrosis. The histopatho-logical findings of the post-mortem specimen showed changes of paraquat poisoning. The sodium dithionate test confirmed the presence of paraquat both in urine and serum samples. Samples sent to the government analyst confirmed the poison as paraquat.

Focus group discussions with different stakeholders showed that paraquat-based pesticides are widely used as a catalyst during brewing of kasippu. After piercing the cap of the bottle, they hang the pesticide bottle over the distilling cocktail. They believe that when the pesticide evaporates due to the heat, some particles of the pesticide will condense and act as a catalyst for the brew. It is thought that this mechanism not only increases the strength but also the quality of the product. We found focus group members who themselves practice this method.

During this unfortunate episode, the paraquat bottle had fallen into the container and contaminated the illicit brew. There had been no change in the taste or the odour, but a change in the colour had been noted. This was explained to the consumer as adding an increased amount of nelli fruits, as it was the nelli fruit season. A dealer who bought this product happened to live next to the funeral house. As a tradition, neighbours send food and drink to funeral houses. Visitors who consumed the brew in large quantities had severe symptoms and died.

Due to the chain of events which led a group of people to be acutely poisoned, it was possible to elicit the cause of poisoning. There may be unrecognised cases of chronic poisoning of paraquat due to accumulation of small amounts of paraquat in tissues. Due to unawareness, sporadic cases of acute poisoning may be missed even at postmortem. Clinicians and forensic pathologists should be aware of this novel method of paraquat poisoning.

\section{References}

1. Eddleston M. Patterns and problems of deliberate self poisoning in the developing world. Quarterly Journal of Medicine 2000; 93: 715-31.

2. Lin JL, Leu ML, Liu YC, Chen GH. A prospective clinical trial of pulse therapy with glucocorticoid and cyclophosphamide in moderate to severe paraquat-poisoned patients. American Journal of Respiratory and Critical Care Medicine 1999; 159: 357-60.

3. Eddleston M, Wilks MF, Buckley NA. Prospect for treatment of paraquat-induced lung fibrosis with immunosuppressive drugs and need for better prediction of outcome: a systemic review. Quarterly Journal of Medicine 2003; 96: 809-24.

Shavindra R. Dias, Department of Psychiatry, Faculty of Medicine, University of Peradeniya, Sri Lanka.

Correspondence: SRD, e-mail <shavindra17@yahoo.co.uk>. Received on 8 November 2008 and revised version accepted on 20 April 2009. Competing interests: none declared. 